\title{
INVESTIGATION OF FATIGUE CRACK PROPAGATION IN ADHESIVELY BONDED JOINTS USING FATIGUE TESTING, FINITE ELEMENT ANALYSIS AND NEURAL NETWORKS
}

UDC: $621.791 .052: 539.388 .1$

Orginal scientific paper

https://doi.org/10.18485/aeletters.2019.4.4.5

\author{
Piyush Gaur $^{1 *}$, Ravi Shankar Prasad ${ }^{2}$ \\ ${ }^{1}$ JATC-HBM Research Laboratory, Mechanical Engineering Department, IIT Delhi, India - 110016 \\ ${ }^{2}$ Institute of Engineering and Technology, JK Lakshmipat University, Jaipur, India - 302026
}

\begin{abstract}
:
The current paper presents research aiming at characterizing the fatigue behaviour of adhesively bonded joints. In this study, a new mathematical model to predict fatigue crack propagation rates for adhesively bonded joints has been investigated and presented. The proposed method uses fatigue test data and stiffness data obtained from finite element model of bonded joints. T-peel and single lap shear bonded joints were prepared using aluminium alloy AA5754 and Betamate epoxy adhesive 4601. The fatigue tests were conducted using constant amplitude loading using an $R$ ratio of 0.1 at a frequency of $10 \mathrm{~Hz}$. The FE models used in this work were developed using fracture mechanics tools in Abaqus. The results were post processed to extract energy release rates in form of $J$ Integrals and stress intensity factors. The stiffness results obtained from both experimental testing and numerical studies were combined using appropriate curve fitting models proposed in the literature to estimate the fatigue crack propagation rates and obtained the de-bond curves in the Paris regime for such joints. The crack growth rates were further modelled and validated using neural network technique in MATLAB.
\end{abstract}

\author{
ARTICLE HISTORY \\ Received: 23.09.2019. \\ Accepted: 08.12.2019. \\ Available: 31.12.2019.

\section{KEYWORDS} \\ Adhesive, fatigue, fracture, \\ finite element method, J- \\ Integral, stress-intensity factor, \\ Paris Law
}

\section{INTRODUCTION}

Adhesive bonding is an attractive alternative to other conventional joining methods such as welding and mechanical fastening. Adhesives are widely employed in vehicle structures to reduce noise-vibration and increase crash-worthiness performance [1]. In applications such as aircraft structures and automotive elements, adhesive bonding competes with riveting, welding or bolting [2-5].The main advantage of using adhesives over these conventional joining techniques is its light weight, ability to join similar and dissimilar materials, sound vibration and damping properties, higher fatigue resistance and longer fatigue life [6]. Many industries like aerospace, automotive, biomechanical, transportation, marine, and so forth make use of adhesives. One of the significant limitations when using adhesives in structural applications is their long-term mechanical behaviour which is not understood completely, neither experimentally nor computationally, particularly when the fatigue behaviour of bonded joints subjected to dynamic or cyclic loading [7]. Fatigue is a critical type of loading for adhesively bonded joints. In a fatigue load regime, these joints may fail at a small percentage of static strength $[7,8]$. Hence, the prediction of fatigue behaviour and fatigue strength of adhesively bonded joints is a significant concern in structures subjected to dynamic loading and highly required for the case of fail-safe and damage tolerance design. Fatigue life prediction and durability of bonded joints is 
challenging task due to fatigue crack initiation and propagation, the geometry of bonded joints, type of loading, surface preparation and curing cycles, and complex material behaviour under cyclic loading conditions $[6,8-10]$. However, due to the complexity of different factors involved, the fatigue life prediction of adhesively bonded joints is still at an early stage as compared to fatigue of metals [7].

Adhesively bonded structures are subjected to cyclic-fatigue loads $[4,11]$ and fail in service. Such fatigue failures can occur even when the maximum cyclic load are well below the static strength of bonded materials. The fatigue behaviour of adhesively bonded joints can be divided into three phases as shown in Fig.1: the fatigue cracks initiation (region-I), fatigue crack propagation(region-II) and the final failure (regionIII). In region I, the existence of a threshold value below which there is no failure due to fatigue; in region II, the cyclic fatigue loads produce no crack growth at stress or strain energy release rate remains lower than the threshold value [10]. The relation between $\mathrm{da} / \mathrm{dN}$ and $\Delta \mathrm{J}$ is practically linear. Finally, in region III, there is a fast crack growth rate or sudden failure. In this region, $J_{\max }$ is close to $J_{c}$. There have been many attempts to model the relation between the fatigue crack propagation rate, $\mathrm{da} / \mathrm{dN}$, and the stress intensity range or strain energy release rate. Paris and Erdogan in 1963 gave the relation most commonly used in fracture mechanics [12]:

$$
\left(\mathrm{da} / \mathrm{dN}=\mathrm{C}(\Delta \mathrm{K})^{\mathrm{m}}\right)
$$

where $\mathrm{m}$ and $\mathrm{C}$ are related material constants. This equation is valid only in region II of the crack growth curve and does not include the effect of mean stress. This correlation has also been investigated for adhesively bonded joints by several authors. Lin \& Liechti (1987) [13] stated that for adhesively bonded joints, the correlation between crack growth rates and the stress intensity factor range has the same sigmoidal shape [12] as that of Paris curve shape.

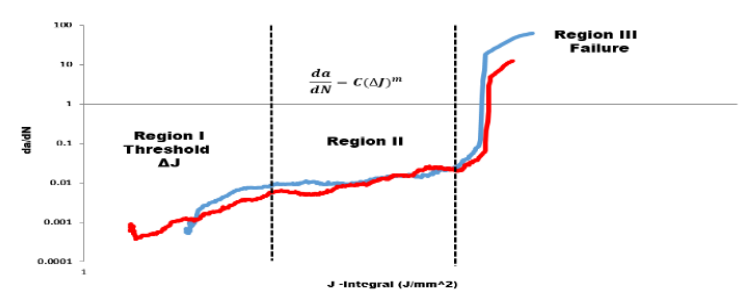

Fig.1. Fatigue crack growth for bonded joints
The fatigue crack propagation has been strongly investigated for bonded joints, and its life depends on the extension of the bonded interface, the load type and the load level [14, 15]. The fatigue crack may propagate under distinct loading combinations resulting in typified crack propagation systems or crack propagation mode mixities [6, 16-20]. Brussat et al (1977) [21] \& Mostovoy \& Ripling (1975) [21] were some of the earlier investigators involved in fatigue studies on adhesively bonded joints. These studies concluded that linear fracture mechanics gives reasonable accuracy in the description of debond growth in adhesives due to fatigue. Lin \& Liechti (1987) [13] correlated de-bond growth to strain energy release rates. They concluded that nonlinear analysis was needed for the computation of energy release rates.Dattaguru et al (1984) [22] also showed that nonlinearities played a crucial role in de-bond of adhesively bonded joints. Kinloch \& Osiyemi (1993) [23] used a double cantilever beam to correlate experimentally measured crack growth rates with analytically obtained strain energy release rates. They determinedfatigue crack growth rate curve with this data and used for fatigue life prediction of single-lap joint specimens. Good agreement was found between the predicted and experimental results. However, none of the above studies presented a method of combining experimental and finite element based to obtain the fatigue crack growth curves for bonded joints. This study thus tries to overcome this limitation.

The neural network is a crucial Matlab tool and is used for modelling and validation of experimental data and find its scope in this area. Earlier Adaptive Neuro-Fuzzy Inference Systems (ANFIS) was used to model the damage and then the measured frequencies were compared to the predicted frequencies to determine the damage [24]. It was found that there are a lots of Artificial Intelligence (AI) techniques and approaches are available in mechanical engineering and some of the Al methods which are used in the field of fracture mechanics are Bayesian Network (BN), Fuzzy Logic (FL), Genetic Algorithm (GA), Artificial Neural Network (ANN) and Case-Based Reasoning (CBR) [25]. In the present work, the fatigue tests on adhesively bonded joints were conducted at $\mathrm{R}$ ratio of 0.1 and a frequency of $10 \mathrm{~Hz}$. A correlation was established to combine fatigue tests data with finite element modelling data to generate crack growth rate curves based on Paris law and SERR components (J-Integral). Out of several curve fitting models [26-33] used earlier for fatigue crack 
propagation, we have preferred and used polynomial curve fitting model to estimate fatigue crack growth rate using the Paris regime. The effort has also been made to use ANFIS to develop a model using experimental data,and the results were validated.

\section{MATERIAL AND METHODS}

This section describes the methodology used in this research to predict fatigue crack propagation rates and obtain crack propagation curves for adhesively bonded joints. The primary inputs to predict crack growth rates are fracture mechanics based test data and finite element data of bonded joints. The fatigue tests were conducted on T-peel and single lap shear bonded joints followed by $2 D$ models of the joints using standard finite element procedures. A brief introduction to ANFIS has also been included in this section. Each of these steps is described below.

\subsection{Experimental Protocol}

The fatigue test data for this researchwas obtained by conducting fatigue tests on single lap shear,and T-peel bonded joint configurations. The fracture mechanics based approach was chosen as a method for testing and analysis of bonded joints because fracture tests display a more controlled mode than maximum strength based tests which usually failed catastrophically[5-6,34]. As a result, not only these tests provides a more detailed tests data but also provides a more fundamental understanding of the failure mechanisms of the adhesively bonded joints. The testing was conducted in two stages - specimen preparation and fatigue testing of the joints.

\subsubsection{Specimen Preparation}

The first step was to manufacture the adhesively bonded coupons for testing. To implement fracture mechanics based testing method, pre-crack was introduced in bonded joints by PTFE film. The adherend material used in single lap shear and TPeel bonded joints was AA5754 Aluminium alloy, which are non-heat treatable alloy and may be strengthened by the strain hardening whereas the adhesive used was Betamate Epoxy 4601. The thickness employed for adherends was $2.0 \mathrm{~mm}$ and $3.0 \mathrm{~mm}$ whereas the nominal thickness of the adhesive employed was $0.25 \mathrm{~mm}$. The guidelines for preparation of the single lap shear joints and T- peel bonded joints is given in BS ISO 4587:2003 and ISO 8510-1:1990 standards. The geometry of single lap shear and T-peel bonded joints employed is shown in Fig.2, $23 \mathrm{~mm}$ overlap size was used in these joints because the size is typically employed for aluminium car body designs employing selfpiercing rivets in Jaguar Land Rover cars [35]. For different sheet thickness combinations, the joints were designated as T22B, T23B, and T33B for Tpeel and LS22B, LS23B for single lap shear joints.

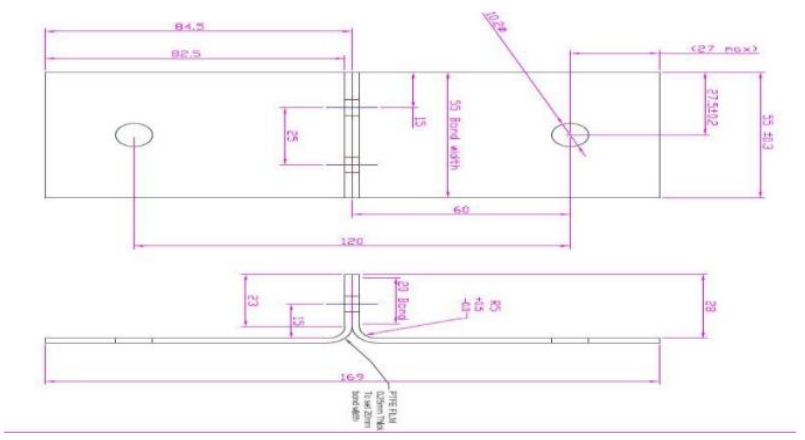

a)

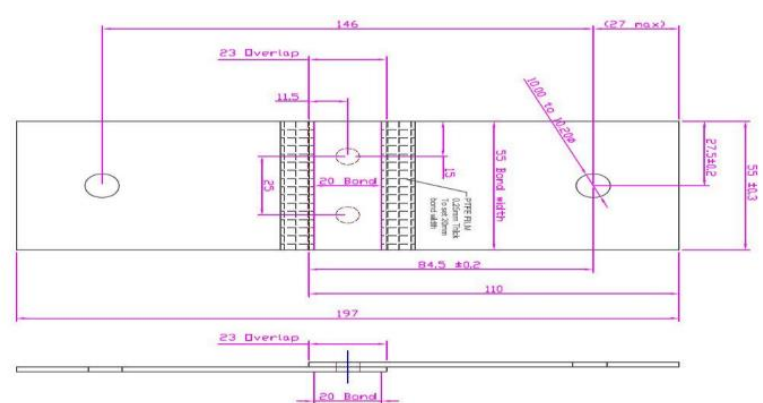

b)

Fig.2. Geometry of T-Peel and Single lap-shear bonded joints (All Dimensions are in $\mathrm{mm}$ )

The aluminium sheets used in manufacturing $T$ peel adhesive joints were phosphoric acid pretreated. Hence, there was no need to clean the surface of the sheets. The advantage of using phosphoric acid pre-treatment over other pretreatment methods like silica pre-treatment is presented in studies [36-39]. The pre-crack employed in T-peel bonded joints were $3.0 \mathrm{~mm}$, $5.5 \mathrm{~mm}, 7.0 \mathrm{~mm}$ and $9.5 \mathrm{~mm}$. For single lap shear joint, only one precrack of $3.5 \mathrm{~mm}$ was employed due to less availbility of these joints. The process of making bonded joints starts with setting proper fixture at the edge of the table as shown in Fig.3(a). Two holes were drilled $10 \mathrm{~mm}$ to $10.2 \mathrm{~mm}$ from the end of each edge ( $27 \mathrm{~mm}$ from each edge) of each joint.To hold the sheets firmly,themetallic strip was inserted on the sheets that work as a spacer. The sheets were clamped by using $G$ clamps which ensured that the front face of the fixture remains parallel to the sheets. PTFE tape 
was then applied across the fillet of the sheets as shown in Fig.3(b).The next step was to put the bead of adhesive on the sheets. The epoxy adhesive is very sticky and viscous. Like other fluids, the adhesive becomes less sticky, if it is heated and hence, it was necessary to heat the high-pressure glue gun with the help of ablower. After heating the glue gun, the adhesive was then put on the sheets by keeping the sheets in one line. To induce pre-crack in these joints, the adhesive bead was not put on the PTFE tape starting from its edge equal to crack length, i.e. to have a $3 \mathrm{~mm}$ pre-crack, the adhesive was only put in $20 \mathrm{~mm}$ overlap length $(23-3=20 \mathrm{~mm})$. The similar procedure was followed while introducing other pre-cracks, i.e. $5.5 \mathrm{~mm}, 7 \mathrm{~mm}$ and $9.5 \mathrm{~mm}$. After applying the adhesive, the sheet was clamped on a flat aluminium sheet with the help of dog clips. The short ends were then clamped with G-clamps which provide an extra pressure on adhesive to flow uniformly in each direction. However, care must be taken in putting too much pressure which can dislocate the sheets and PTFE tape resulting into the poor quality of the joint. The final assembly of T-Peel bonded joint for curing is shown in Fig.3(d). Curing was carried out by heating the joints at $180^{\circ} \mathrm{C}$ for 2 hours in an oven. The joints were then stored until the testing was carried out.

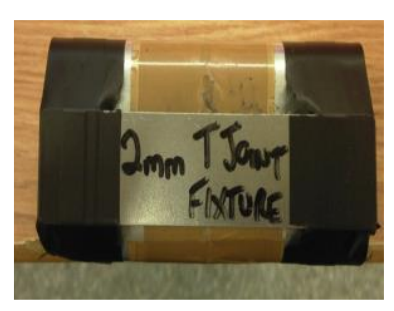

a)

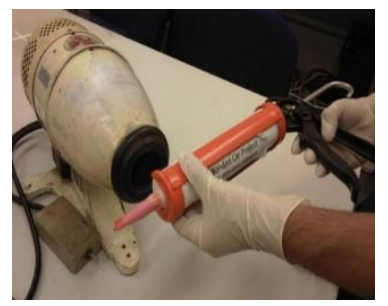

(c)

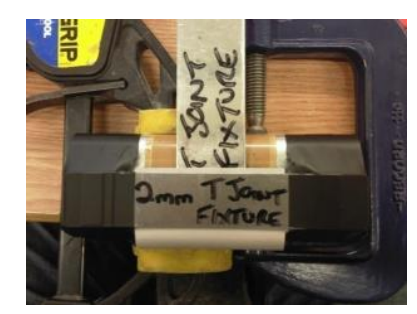

b)

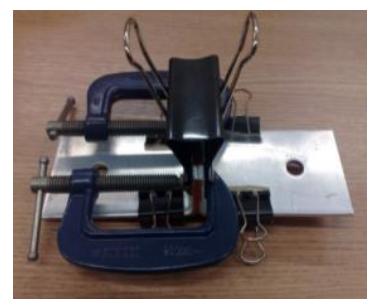

(d)
Fig.3. a) Fixture used for T Peel bonded joints, b) Applying PTFE tape in bonded joints, c) Heating of glue gun containing adhesive, d) Final prepared T-Peel bonded joint

\subsubsection{Fatigue Testing of Bonded Joints}

The second stage was to test the adhesively bonded joints on a fatigue frame (Instron, UK) fitted with $10 \mathrm{kN}$ load cell. The machine used for fatigue tests was a servo hydraulic dynamic testing machine having a load capacity of $10 \mathrm{kN}$ interfaced to a computer for machine control and data acquisition. The tests were conducted under ambient room temperature conditions at a temperature of $23^{\circ} \mathrm{C}$ and a schematic of the test arrangement is shown in Fig.4. All the tests on Tpeel and single lap shear was conducted at a frequency of $10 \mathrm{~Hz}$ using an $\mathrm{R}$ ratio of 0.1 where $\mathrm{R}=$ $P_{\min } / P_{\max }$ and are the minimum and the maximum loads applied over the fatigue cycle respectively.The load used during the test was chosen in such away that it lies below the threshold of adhesive. As soon as the load reaches the adhesive threshold level, the crack starts growing in to the adhesive and the joint finally separated out. Aminimum of three crack lengths were used in the test in order to get a good curve fit. Crack propagations were recorded continuously using a 4-megapixel USB microscope at a rate of 15 frames per second.

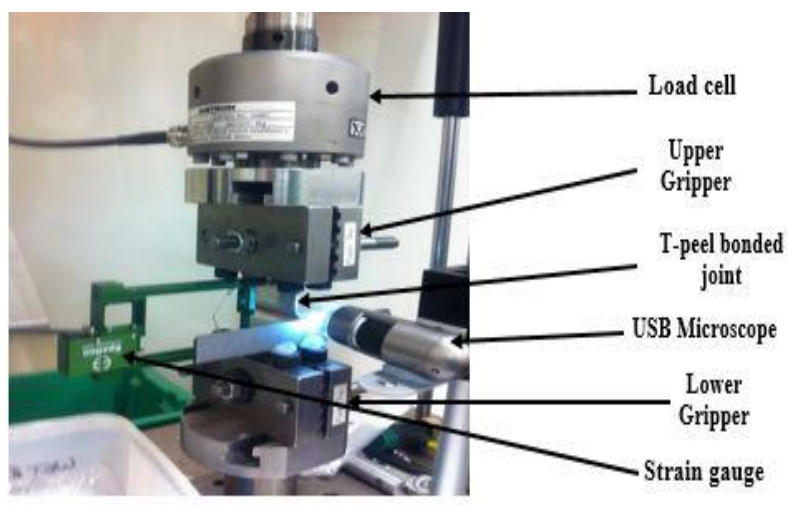

Fig.4. Fatigue test frame used in fatigue testing of bonded joints

\subsection{Finite Element Modelling}

The aluminium to aluminium peel and single lap shear bonded joints with de-bond used for numerical study is analysed with Simulia Abaqus $^{\mathrm{tm}}$ (Dassault Systems) finite element analysis package. The geometric model development, problem setup and meshing of the twodimensional models were carried out by using Hypermesh pre-processor (Altair Engineering). The selection of a finite element, meshing approach, geometry and boundary conditions and modelling of cracks is discussed in this section.

\subsubsection{Meshing Methodology}

The meshing of $\mathrm{T}$ peel and single lap shear bonded joints is a challenging task due to the 
presence of a very thin adhesive layer compared to the overall dimensions of these joints. The addition of the fillets at the end of the overlap of these joints further complicates the meshing of these joints. There are numerical singularities in the geometry of single lap shear and $\mathrm{T}$ peel bonded joints due to the presence of the rectangular adherends and fillet corners. Hence, the selected mesh should adequately represent the deformed as well as the undeformed shape of the bonded joints. The representative FE model of T-peel bonded joints and single lap shear joints is shown in Fig.5.

A continuous mesh is being used in these joints, which may transition from the fine mesh in the adhesive region to the coarse mesh in the adherends region while maintaining the continuity by sharing an equal number of nodes between the elements. This method of meshing the adhesives requires some partitioning of the adherends geometry, and thus each region was meshed very easily by varying the element size. In the adhesive bond region, elementswere placed by using *ELSET technique (keyword inthe.inp file) by sharing an equal number of nodes in Abaqus. The adhesive fillets were not modelled to reduce complexity in the FE models.

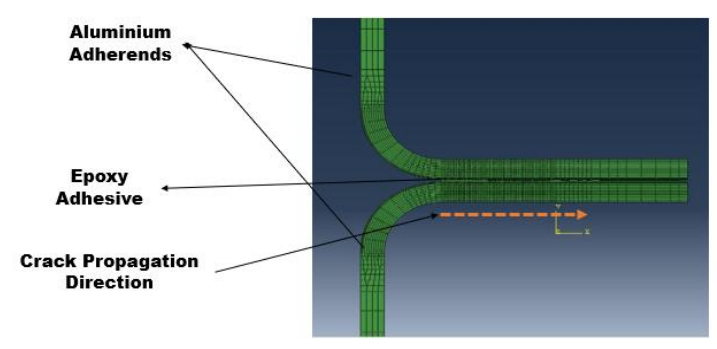

a)

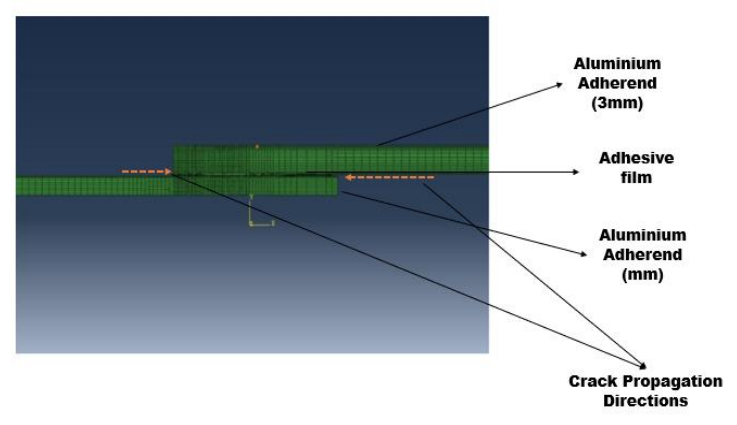

b)

Fig.5. FE models of a) T- Peel Bonded Joint, b) Single lap Shear bonded Joint

2.2.2 Type of Element and Material Properties Used

All the FE models of bonded joints were modeled under plane strain conditions. Hence the two-dimensional plane strain quad shell element, known as a CPS4 element in Abaqus material library has been used in meshing the adhesive bond region. The main reason for using quads element is the better convergence rate as compared to triangular shell element. In the adhesive bond region, a fine mesh size of $0.25 \mathrm{~mm}$ was used and are congruent meshes in both the adherends. The element size used to mesh the adherends were $2.0 \mathrm{~mm}$. The plane strain elements employed in FE models predicted the Von Mises stresses across in the bond line region and displacements were then calculated along $Y$ axis to calculate the stiffness of the joints. Owing to the bending of the joints in the adherends, conventional 2D shell elements may suffer shear locking that generates shear stress in the elements, resulting in a stiffer response under bending conditions than the actual stiffness of the structure. Thus, the formulation of shell elements used in themeshing of bonded joints was changed to incompatible mode to avoid shear interlocking under bending. In addition to the standard displacement degrees of freedom, incompatible mode elements have incompatible deformation modes added internally to the elements. This reduces the overall computational time of the analysis. The material properties used for adherends and adhesive used in FE models of single lap shear and $\mathrm{T}$ Peel bonded joints are presented in Table 1.

For static loading, the boundary conditions were applied in the form of fixed displacements at the adherend edge in T-peel and single lap shear bonded joints. The free edges of the bonded coupons were remained free to strain the lefthand corner of the joint is held in $\mathrm{x}$ and $\mathrm{y}$ directions, and the subsequent nodes are held in $y$-direction only. Free straining is allowed in thex-direction. For T-peel bonded joints, the total load applied to FE models was $1.2 \mathrm{kN}$, and $3.0 \mathrm{kN}$ whereas the total load applied was $8.0 \mathrm{kN}$ for single lap shear bonded joints.

Table 1: Material properties of adhesive and adherends used in FE model

\begin{tabular}{|c|c|c|c|}
\hline Materials & $\begin{array}{c}\text { Elastic } \\
\text { Modulus } \\
\text { (MPa) }\end{array}$ & $\begin{array}{c}\text { Poisson' } \\
\text { s Ratio }\end{array}$ & $\begin{array}{c}\text { Density } \\
\left(\mathbf{k g} / \mathrm{mm}^{3}\right)\end{array}$ \\
\hline $\begin{array}{c}\text { Adhesive: Betamate } \\
\text { Epoxy 4601 }\end{array}$ & 3500 & 0.45 & $\mathrm{NA}$ \\
\hline $\begin{array}{c}\text { Adherend: } \\
\text { Aluminium AA5754 } \\
\text { Alloy }\end{array}$ & $6.89 \mathrm{E}+04$ & 0.33 & $2.70 \mathrm{E}-03$ \\
\hline
\end{tabular}




\subsubsection{Modelling of Cracksand J Integral Extraction}

Three failure locations were modelled in FE models of bonded joints is shown in Fig.6(a). This failure location includes interfacial failure at the adhesive/adherend interface, cohesive failure of the adhesive within the bond line and cohesive failure of the adherends. All the FE bonded joint models were run as global and submodels. Element deletion technique is used in the bonded joints to represent opening and propagation of cracks. At every time step of the analysis, each element set was deleted by offsetting the nodes associated with deleted elements. Each global model consists of 19 global steps. Each step simulates a crack growth of $0.5 \mathrm{~mm}$. The minimum crack length used in bonded joint models is $0.5 \mathrm{~mm}$ and the maximum crack length modelled is $9.5 \mathrm{~mm}$. A typical global model is shown in Fig.6(b).

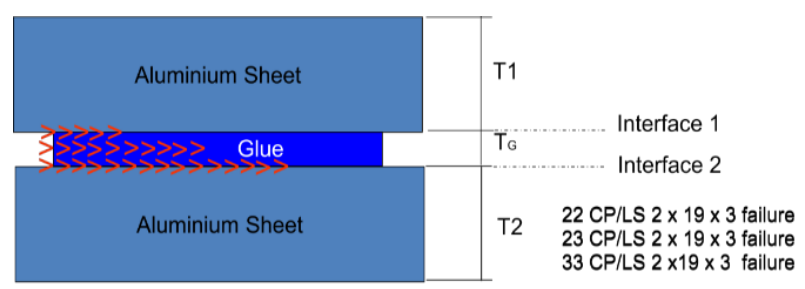

a)

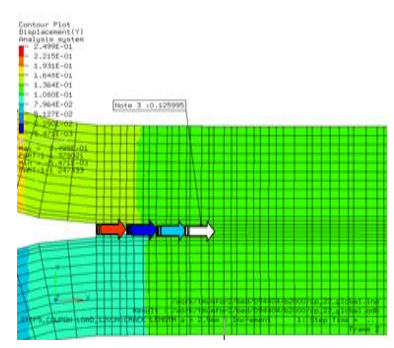

b)

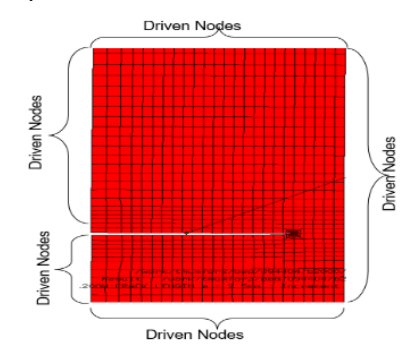

c)
Fig.6. a) Failure locations modelled in2D FE model of bonded joints, b) Global model of T peel bonded joint, c) Submodel used for extraction of stress intensity factor and energy relewase rates

The submodelling approach has been used to extract out the strain energy release rate of these joints. One of such sub model is shown in Fig.6(c). The sub-model occupies the same global physical space as the un-deformed global model. The effectiveness of the sub-modelling approach is used in modelling adhesively bonded joints by Bogdannovich \& Kizhakkethara (1999) [40] \& Wu \& crcocmbe (1996) [41]. They suggest that bond line areas in FE model may require more complex uniform mesh to predict the strain energy release rates accurately. The displacement and the stresses for thereduced region can be calculated in several steps. The remeshed sub-model can be inserted back into the global model and analysis can be re-performed for the full combined model. The energy release rates were extracted in the form of $J$ integral due to its path independent nature through a sub routine program developed using PERL scripting language.

\subsection{Methodology for Determination of Crack Growth Rates and Curves}

The procedure of the method employed in this research to calculate fatigue crack propagation rates are outlined below:

1. The stiffness drop was calculated by post processing the results of 2D FE models by using the displacements obtained and the load applied in FE models. The energy release rates for damage models were extracted out in the form of J-Integrals and stress intensity factors by using a sub routine program developed using PERL script. The curves were then plotted between Energy release rates and stiffness with respect to crack length as shown in Fig.7(a-b) for one of the joints.

2. The relationship between stiffness and energy release rates with respect to crack length were obtained by fitting a polynomial curve in the results of 2D damage models. The suitability of polynomial curve fitting models in fatigue test data is well documented and presented in $[29,30,42]$.The stiffness drop was also obtained in fatigue test data of T-Peel and lap shear bonded joints by using load range and displacement range.

3. The mathematical equations obtained by curve fitting the FE results of damage models were used to calculate the crack length and energy release rates in the fatigue test data of T-Peel bonded joints for different crack lengths. The rate of change of cycles and crack was then calculated by taking the successive differences of the crack length and cycles to failure in fatigue test data. The fatigue crack propagation rates were then found by dividing the rate of change of crack length by therate of change of cycles as given below:

$$
\begin{gathered}
\text { Change in crack length }(\mathbf{d a})=a_{j}-a_{i}, \\
\text { Changes in cycles }(\mathbf{d N})=N_{j}-N_{i}
\end{gathered}
$$

Where $a_{i}$ and $a_{j}=$ crack length in $\mathrm{i}^{\text {th }}$ step and $\mathrm{j}^{\text {th }}$ step in ' $\mathrm{mm}$ ' respectively. $\mathrm{N}_{\mathrm{i}}$ and $\mathrm{N}_{\mathrm{j}}=$ No. of cycles in $\mathrm{i}^{\text {th }}$ step and $\mathrm{j}^{\text {th }}$ step respectively. $\mathrm{i}=$ No. of experimental steps, and $\mathrm{j}=\mathrm{i}+1$.

Fatigue crack growth rate $(\mathbf{d a} / \mathbf{d N})=\left(a_{j}-a_{i}\right) /\left(N_{j}-N_{i}\right)$ 
4. The crack growth rates curves thus can be plotted by using the calculated fatigue crack propagation rates and cycles to failure on log log plot.

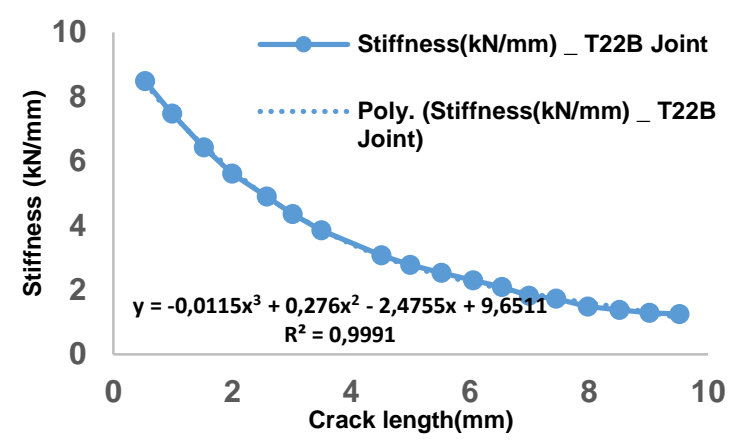

a)

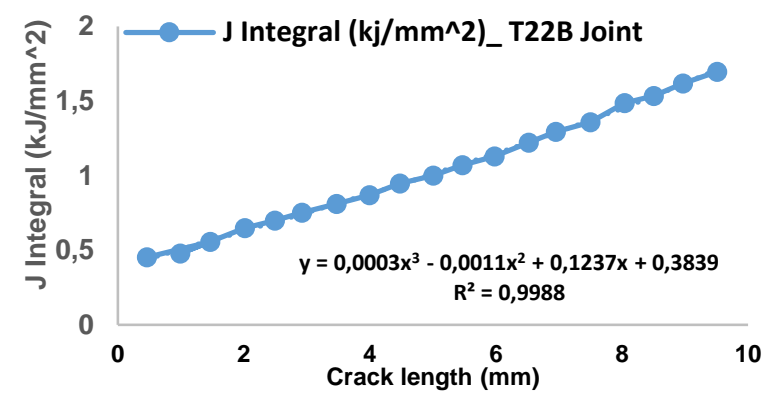

b)

Fig.7. a) Stiffness vs. crack length, b) J-integral vs crack length curves obtained from FE models

\subsection{Adaptive Neuro-Fuzzy Inference Systems (ANFIS)}

ANFIS is a combination of the neural network and the fuzzy inference system. The fuzzy logic takes into account the imprecision and uncertainty of the system that is being modeled while the neural network gives it a sense of adaptability. Using this hybrid method, at first an initial fuzzy model along with its input variables are derived with the help of the rules extracted from the input output data of the system that is being modeled. Next the neural network is used to fine tune the rules of the initial fuzzy model to produce the final ANFIS model of the system. In this proposed work ANFIS $[43,44]$ is used as the backbone for the identification of real world systems. The crack growth rate data was modeled using fuzzy inference system sujeno and adaptive network combination.

Data were modeled to get crack growth rate when value of stiffness, cycles, crack length, Jintegral, change in cycle and change in crack length are part of the input membership function. Plots for the data analysed are shown in Fig 8(a-d). Data were also modeled using ANFIS to validate the results obtained and plotted for the specimens
T33B with different precrack length $(3 \mathrm{~mm}, 5.5 \mathrm{~mm}$, $7 \mathrm{~mm}, 9.5 \mathrm{~mm}$ ). Plots are as shown in Fig 12(a-i).

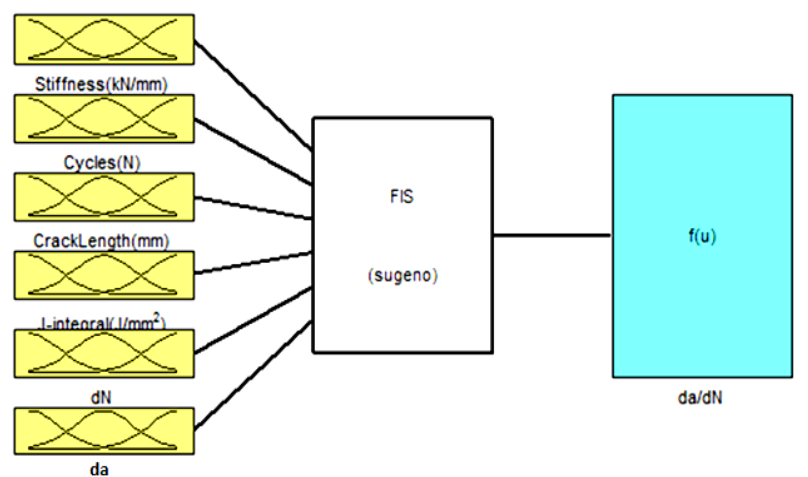

(a)

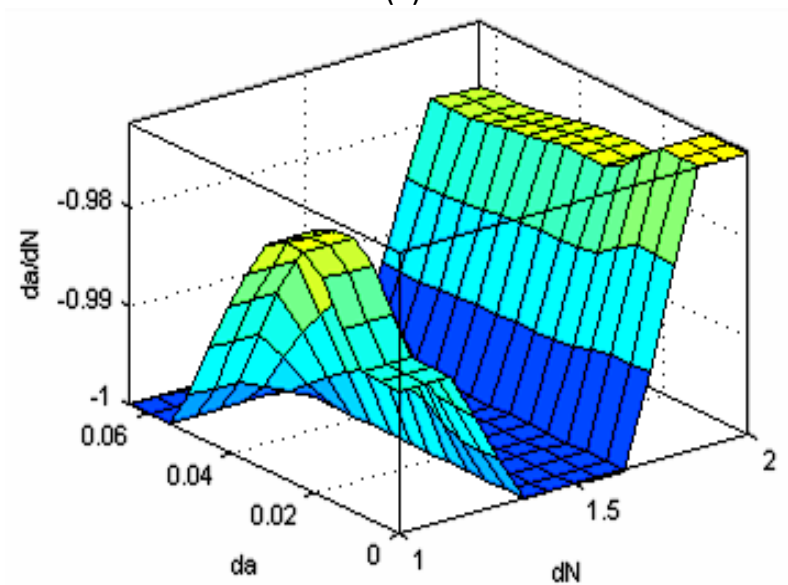

b)

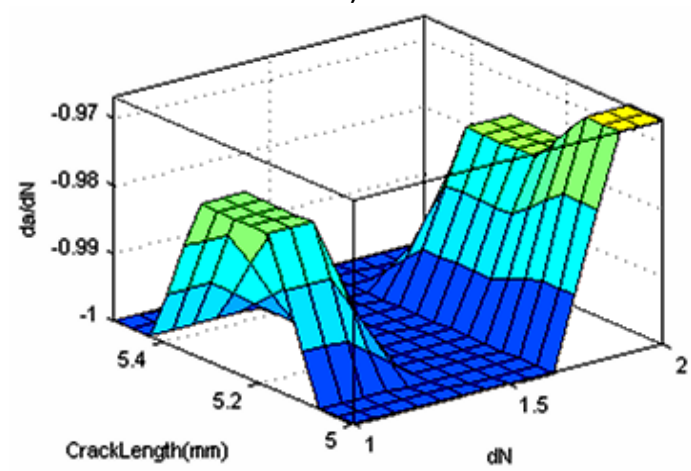

c)

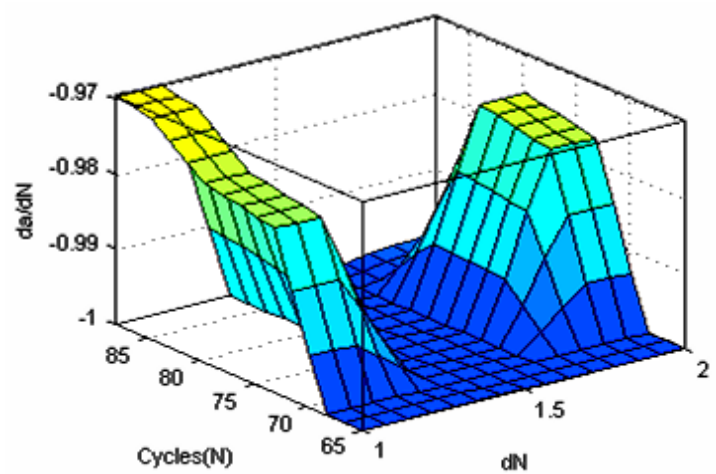

d)

Fig.8. a) Structure of ANFIS model when J-integral and stiffness are included, b) Variation of $d a / d N$ using ANFIS Model with variation in da\&dN, c) Variation of $d a / d N$ using ANFIS Model with variation in Crack Length \& $d N$, d) Variation of da/dN using ANFIS Model with variation in Cycle Length \&dN 


\section{RESULTS AND DISCUSSIONS}

The fracture mechanics data from the tests conducted on T-Peel and lap shear bonded joint specimens have been used to predict the fatigue crack propagation rates, when subjected to cyclicfatigue loading, via the equations obtained by fitting the stiffness and energy release rate curves obtained from finite element results. As noted previously, the finite element based models were developed by modelling the crack in the bond-line thickness upto $9.5 \mathrm{~mm}$ as for the same joint test specimens which were prepared by inducing precracks of different lengths.

The fatigue testing on bonded joints was conducted in two stages. The first stage includes the preparation of T-Peel and single lap shear bonded joints with different crack lengths. The second stage was to test these joints on an Instron fatigue testing machine to obtain the detailed fatigue tests data. During testing of these joints, a small load was applied to all of the bonded coupons to ensure that adhesive does not crack during stiffness measurement. The loadwas chosen in such a way that it lies below the threshold of adhesive. As soon as the load reaches the threshold level, the crack starts growing into the adhesive, and the joints finally separated out. A minimum of three crack lengths was employed in this method to obtain a good fit in crack growth rate curves.

T-peel bonded joints were the first tested configuration. T22B joints were tested first. The pre-cracks introduced in these joints were $3 \mathrm{~mm}, 5.5 \mathrm{~mm}, 7.0 \mathrm{~mm}$ and $9.5 \mathrm{~mm}$. Some precracked samples of T22B joints were ran for about 3000 to 5000 cycles at the same load level without growing the crack into the adhesive. The loaddisplacement data recorded for these test were used for obtaining the stiffness values for each crack length. These joints were regarded as no run to failure joints (NRTF) under the derived curves. The same joints tested above were run at a higher load above the threshold level to achieve crack propagation and fails the joint. On these tests, the crack started growing as soon as the higher load was applied; even the load applied was $0.1 \mathrm{kN}$ higher. The joints tested under these loading conditions were marked as run to failure (RTF). This data was used in calculating the stiffness values from the points where displacement starts to change and crack starts growing through the adhesive.T33B joints were tested with $3.0 \mathrm{~mm}$, $5.5 \mathrm{~mm}, 7.0 \mathrm{~mm}$ and $9.5 \mathrm{~mm}$ pre-crack length.
These joints were tested at a load level of $0.5 \mathrm{kN}$, $1.0 \mathrm{kN}$ and $1.5 \mathrm{kN}$. T23B joints were tested for 3.0 $\mathrm{mm}, 5.0 \mathrm{~mm}$ and $7.0 \mathrm{~mm}$ pre-crack lengths. These joints were tested at load levels of $0.5 \mathrm{kN}$ and 0.6 $\mathrm{kN}$ respectively. The surfaces failed under these tests are all cohesive as shown in Fig.9 (a). The Tpeel joints with different sheet thickness were tested at low load levels, i.e. $0.5 \mathrm{kN}$ and $0.6 \mathrm{kN}$. This low level oftheload was used to find the load level below the threshold level of the adhesive. This level for the adhesive in these joints was noted between $50 \mathrm{k}-100 \mathrm{~K}$ cycles. The failure observed in these joints was an interfacial failure as shown in Fig.9(b) for every pre-crack length. The fatigue test results for these joints are shown in Table 2. The test result for T23B joints with $9.5 \mathrm{~mm}$ was not included in the test results and was deemed to be failed because of the detachment of strain gauge during the test due to high frequency vibrations.

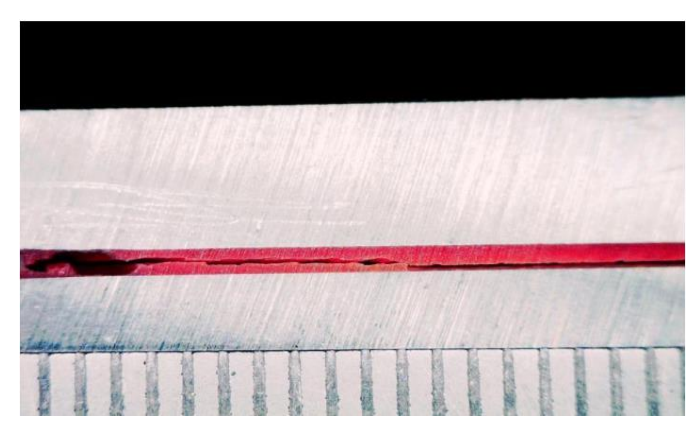

(a)

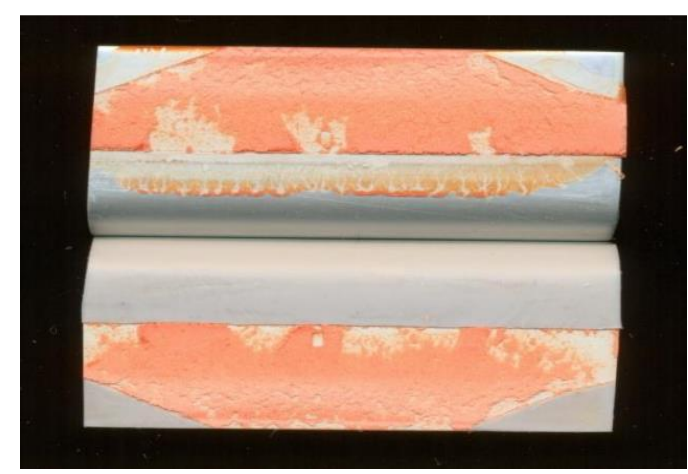

(b)

Fig.9. a) Cohesive failure observed in T33B joint, b) Interfacial failure observed in T23B joint

Whereas the single lap shear joints which were fatigue tested was pretreated with PT2 silica pretreatment and was cured at $180^{\circ} \mathrm{C}$ for two hours. The first series of lap shear joints tested was LS22B joints. Three tests were conducted on LS22B joints. The load applied in these tests was 8 kN. Crack propagation was recorded by using USB microscope. The failure observed in these joints was interfacial failure across the top sheet. In first 
and second tests, the crack propagated from the front side which was quite easy to record and measure whereas, in thethird test, the crack instead of propagating from the front propagates from the rear side of the joints as a result of which the crack propagation was not recorded.The LS23B joint is the other single lap shear configuration tested in fatigue. Two tests were conducted by applying a load of $9 \mathrm{kN}$. The failure observed in these joints was interfacial failure across the top sheet of the joints. The fatigue test results for these joints are shown in Table 3. It was observed from the testing of single lap shear joints that they have the poor fatigue performance as compared to PAA treated T peeled joints. As soon as the crack initiated into the joint, it propagated very quickly and failed the joint immediately. Whereas in case of PAA treated joints, the crack propagates cohesively through the adhesive film for T22B and T33B joints and this was the reason for superior fatigue performance over single lap shear joint.

Table 2: Fatigue test result of T-Peel bonded joints

\begin{tabular}{|c|c|c|c|c|}
\hline $\begin{array}{c}\text { S } \\
\text { No }\end{array}$ & $\begin{array}{c}\text { Joints } \\
\text { type }\end{array}$ & $\begin{array}{c}\text { Crack } \\
\text { length(mm) }\end{array}$ & $\begin{array}{c}\text { Load } \\
\text { Applied(kN) }\end{array}$ & $\begin{array}{c}\text { Cycles to } \\
\text { Failure(N) }\end{array}$ \\
\hline 1 & T22B & 3 & 0.6 to 0.7 & 6,049 \\
\hline 2 & T22B & 5.5 & 0.6 to 0.7 & 6,000 \\
\hline 3 & T22B & 7 & 0.6 to 0.7 & 5,568 \\
\hline 4 & T22B & 9.5 & 0.6 to 0.7 & 2,171 \\
\hline 5 & T33B & 3 & 1 & 750,255 \\
\hline 6 & T33B & 5.5 & 0.5 & 43,059 \\
\hline 7 & T33B & 7 & 0.5 & 146,917 \\
\hline 8 & T33B & 9.5 & 1.5 & 54000 \\
\hline 9 & T33B & 5.5 & 1.0 & 666,738 \\
\hline 10 & T23B & 3 & 0.5 & 284,702 \\
\hline 11 & T23B & 5.5 & 0.5 & 874,721 \\
\hline 12 & T23B & 7 & 0.6 & 146,917 \\
\hline
\end{tabular}

Table 3: Fatigue test result of Single lap shear bonded joints

\begin{tabular}{|c|c|c|c|c|}
\hline $\begin{array}{c}\text { S } \\
\text { No }\end{array}$ & $\begin{array}{c}\text { Joints } \\
\text { type }\end{array}$ & $\begin{array}{c}\text { Crack } \\
\text { length(mm) }\end{array}$ & $\begin{array}{c}\text { Load } \\
\text { Applied(kN) }\end{array}$ & $\begin{array}{c}\text { Cycles to } \\
\text { Failure(N) }\end{array}$ \\
\hline 1 & LS22B & No Pre-crack & 8 & 55,000 \\
\hline 2 & LS22B & No Pre-crack & 8 & 80,000 \\
\hline 3 & LS22B & No Pre-crack & 8 & 76,700 \\
\hline 4 & LS23B & 3.5 & 9 & 37,000 \\
\hline 5 & LS23B & 3.5 & 9 & 42,000 \\
\hline
\end{tabular}

The results obtained from experimental testing and finite element modelling were then processed using appropriate curve fitting models presented in section 2.3. The fatigue crackspropagation curves obtained using the methods presented above for $T$ peel and single lap shear bonded joints is shown in Fig.10(a-d). It is clear from that the curves obtained for T22B joints resembles the nature and shape of Paris-Ergodan law. The curves of T22B joints for all crack lengths are lying very near to each other and indicates greater fatigue crack growth rate with large crack length $(9.0 \mathrm{~mm})$. For T23B joints, for $3.0 \mathrm{~mm}$ crack, there is slow crack growth rate uptill region 1 and then the joint finally got separated with a rapid crack growth in region 2 and 3 . For $5.5 \mathrm{~mm}$ cracked joints, the crack growth rate decreases in region 1, i.e upto 2500 cycles. However, after certain number of cycles, i.e. after 3500 cycles, due to excess vibration, the strain gauge was detached from the test rig. These no of cycles beyond this points were deleted from test data. There is then steady crack growth rate in region 2 and finally the joints separates out with rapid crack growth in region 3. The similar trend was observed for T23B joints with $7.0 \mathrm{~mm}$ crack. The $9.0 \mathrm{~mm}$ crack test was not included in the final results because of the test failure. Interfacial failure as shown in is observed in these joints for all crack lengths. Similar trends were observed for T33B joints too for every crack length. However, a sharp drop in the crack propagation was observed in region 1 of the CGR curves of these joints. This could be because of the strain gauge attached on the adherends surface picked up high vibrations during the initial phase of fatigue test, which resulted in quick stiffness drop in initial phase of these curves. Whereas for single lap shear joints, there is a rapid crack growth until region 1. As soon the crack crosses region 1 , the crack propagation stabilises, becomes slow and follows a linear trend until the end of region 2 . After crossing region 2 , the crack propagation rate increases and finally the joints separated out in region 3. The nature and shape of the CGR curves follows the Paris-Ergodan law except that there is a rapid crack propagation within the joints. This effects could be attributed because of effect of PT2 silica pretreatment and mixed mode observed at the corners of these joints. The failure observed in these joints were interfacial across the top sheets of these joints. The CGR curves of LS23 bonded joints were not presented here due to observance of dual crack growth in these joints. 


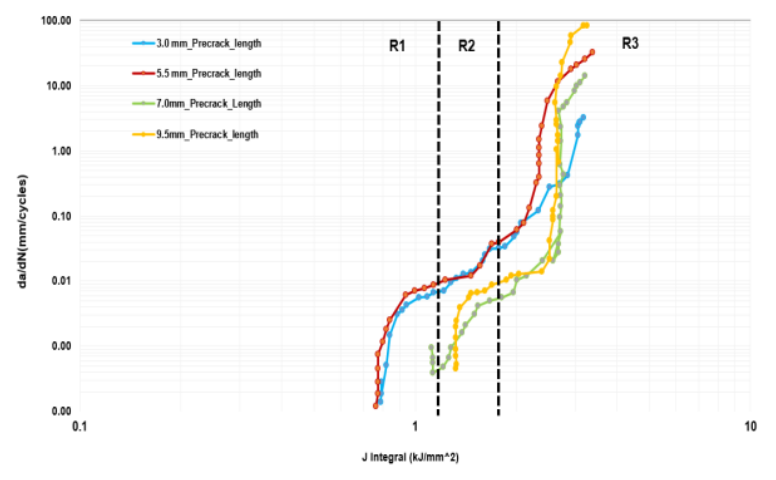

a)

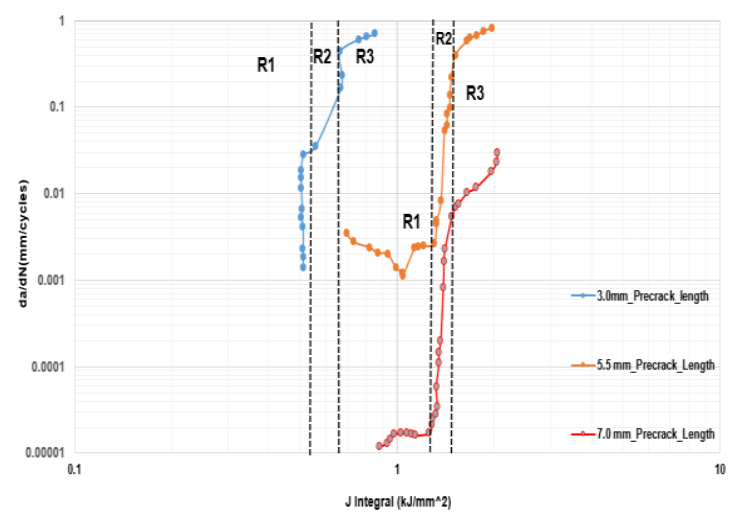

b)

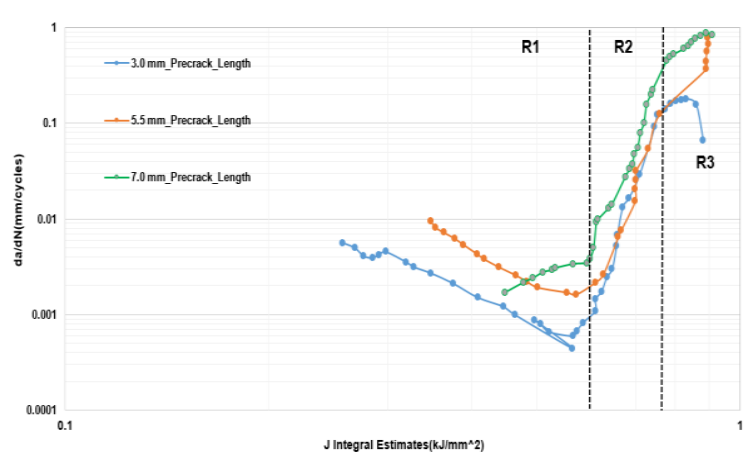

c)

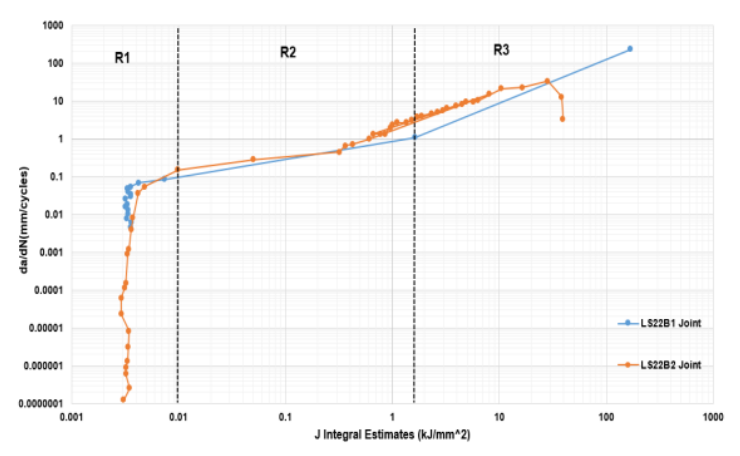

d)

Fig.10. Crack growth rate curves of a) T22B joints, b)T33B, c) T23B, b) Single lap shear, LS22B joints (R1 Region 1, R2- Region 2, R3- Region 3 of CGR curves)

The crack propagation was recorded and monitored for T33B, T23B and LS22 joint by using
USB microscope during the test. The recording of the crack propagation in some of the joints was quite useful in seeing the type of failure associated with the particular bonded joint. It was also noted from fatigue tests that the joints with small crack lengths are subjected to high cycle fatigue ( greater than $10^{5}$ cycles) and with larger crack lengths are subjected to low cycle fatigue failure. It should also be noted that the tests conducted on bonded joints for this methodology were all constant amplitude tests which reveal that there is an increase in crack length with the number of loading cycles. The method was then validated against the crack propagation videos recorded for T-Peel and single lap shear bonded joints. The method was validated in two stages. In the first stage, the crack lengths were measured using the crack propagation videos until the point of final failure at subsequent time intervals. The respective time was noted,and the number of cycles was calculated for each measured crack lengths. In the second stage, the respective crack lengths were taken from the fatigue test data at the same number of cycles. A variation of crack length with respect tonumber of cycles were plotted for each crack length measured from videos and experimental data. One of such variations plotted for T33B joints with different crack lengths, i.e. $3.0 \mathrm{~mm}, 5.5 \mathrm{~mm}, 7.0$ $\mathrm{mm}$ and $9.5 \mathrm{~mm}$ is shown in Fig.11(a-d). A good correlation was observed between the measured crack length from videos and experimental data for the precrackedjoints. The correlation increases with the increase in crack length and becomes more stable at larger crack length, i.e., more stable for $9.5 \mathrm{~mm}$ precrack. Process was modeled and results were validated using ANFIS. The effect of various parameters as above mentioned has signifant effect on the crack growth rate of bonded joints. The effect of the variation in the value of process parameters on crack growth rate can be observed in plots shown in Fig.8 and Fig.12.

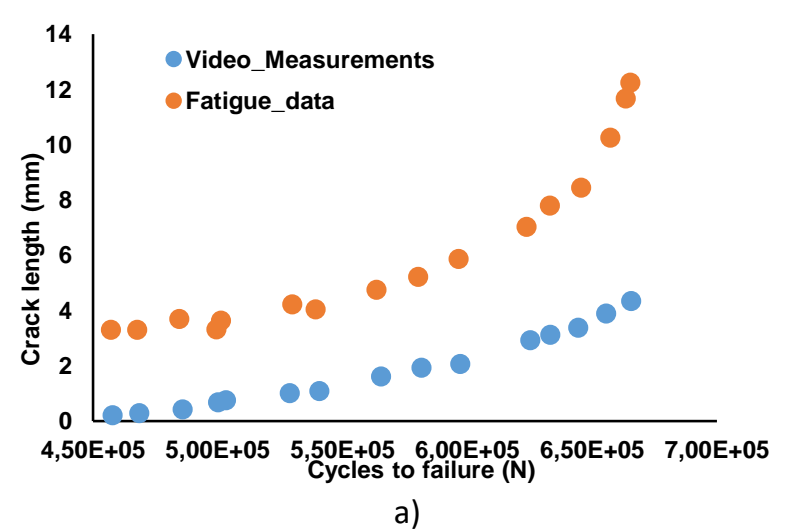

a) 


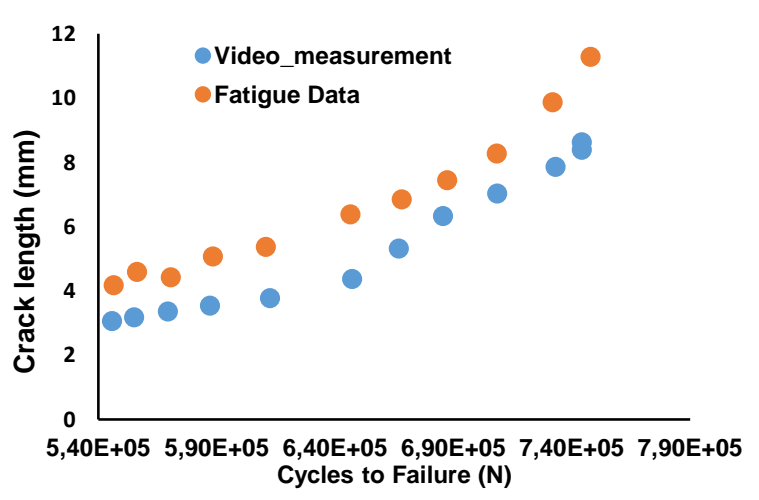

b)

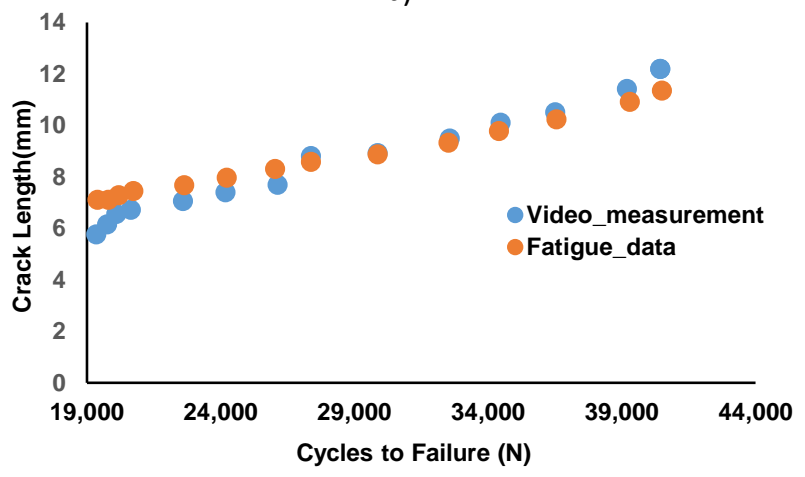

c)

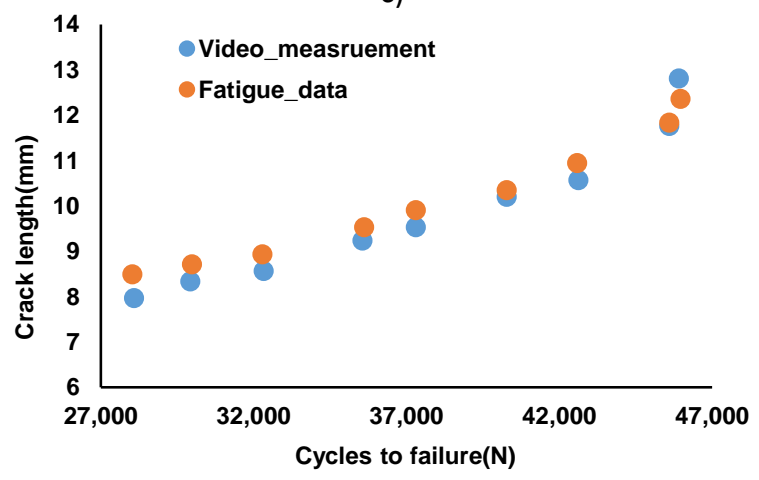

d)

Fig.11. Crack length vs. Cycles to failure curves for T33B joints with a) $3.0 \mathrm{~mm}$, b) $5.5 \mathrm{~mm}$, c) $7.0 \mathrm{~mm}$, d) $9.5 \mathrm{~mm}$ precrack lengths

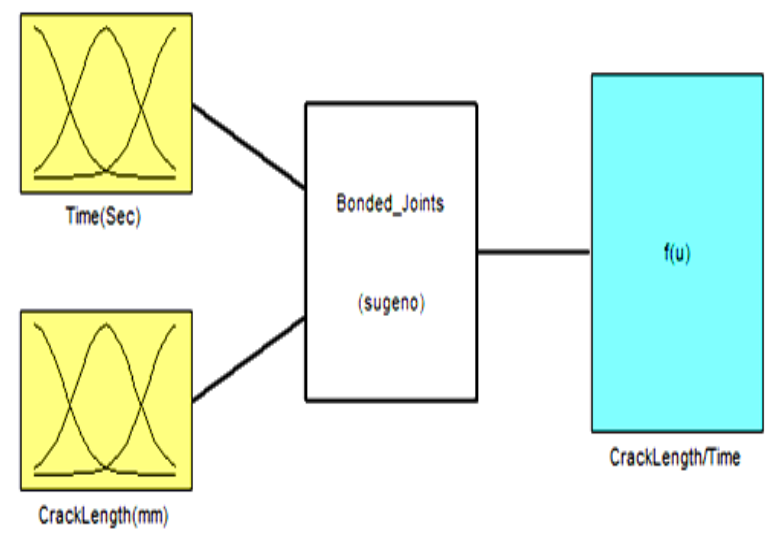

a)

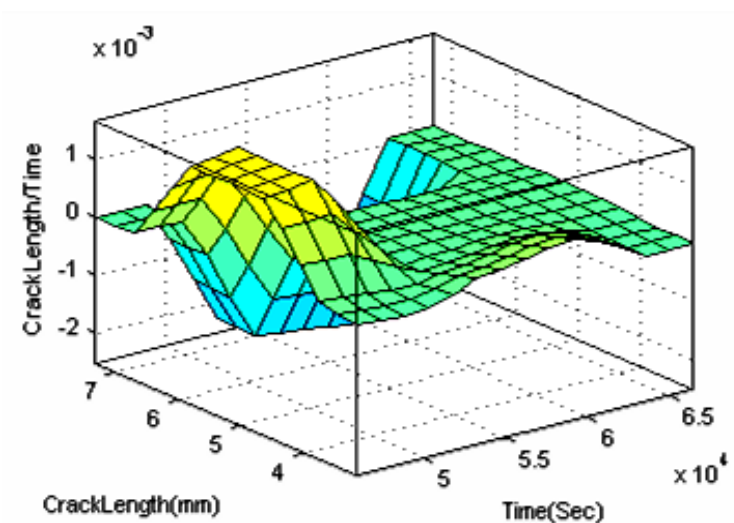

b)

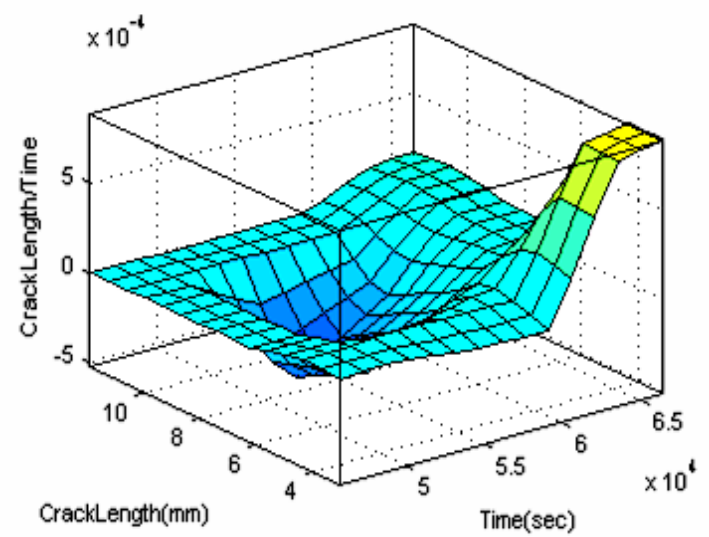

c)

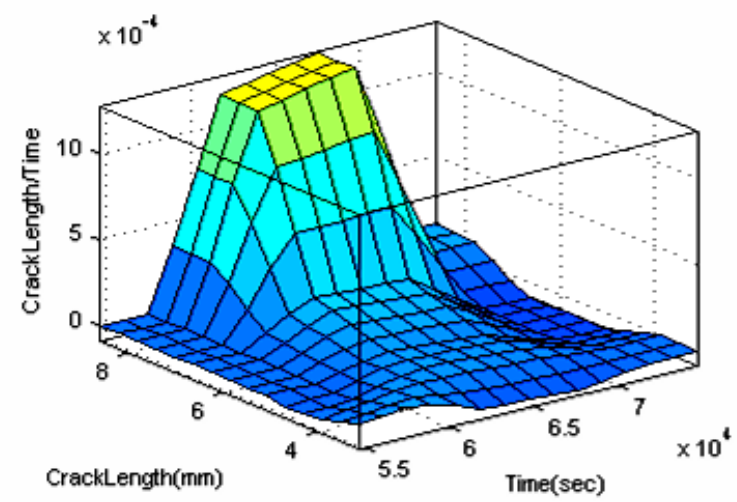

d)

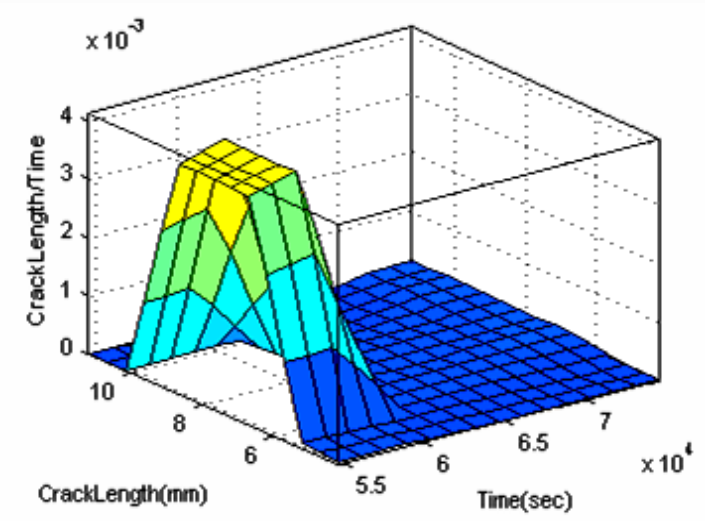

e) 


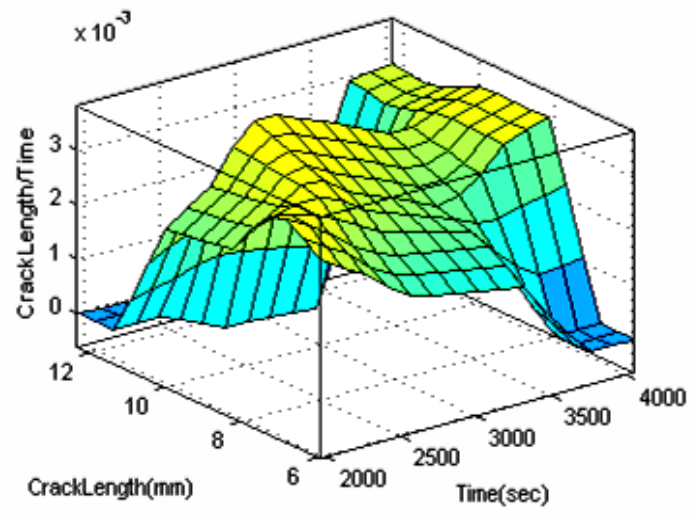

f)

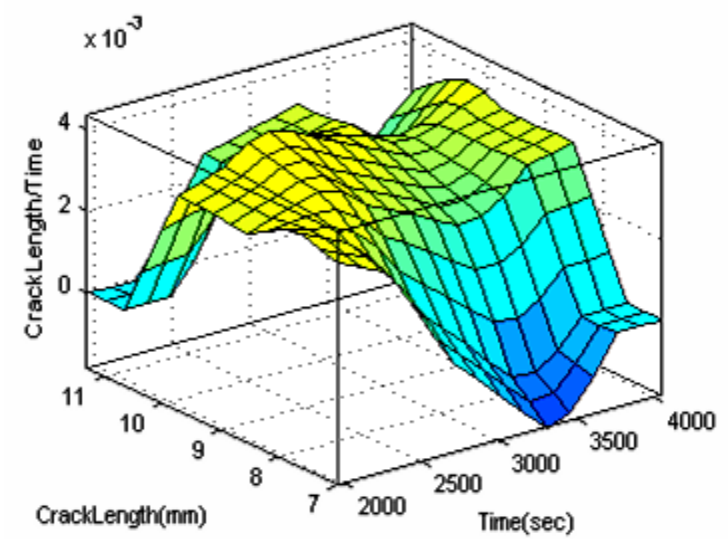

g)

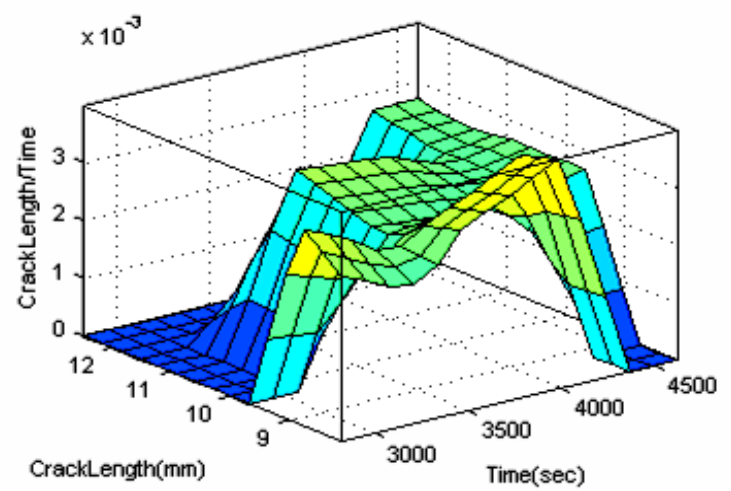

h)

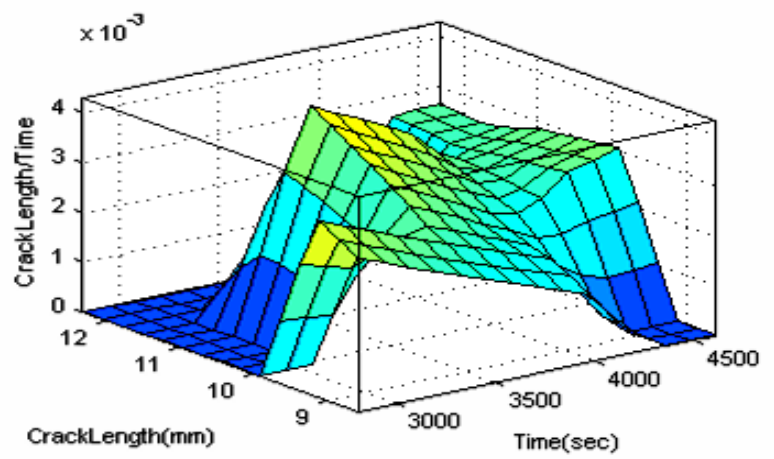

i)

Fig.12. a) Structure of ANFIS Model for Crack Length vs Time, b) ANFIS Model Plot for data obtained using video for T33B with 3mm Precrack, c) ANFIS Model Plot for data obtained using stiffness method in fatigue test data for precrack $3 \mathrm{~mm}$, d) ANFIS Model Plot for data obtained using video for T33B with $5 \mathrm{~mm}$ Pr Precrack, g) ANFIS Model Plot for data obtained using stiffness method in fatigue test data for precrack $7 \mathrm{~mm}$, h) ANFIS Model Plot for data obtained using video for T33B with 9.5mm Precrack, i) ANFIS Model Plot for data obtained using stiffness method in fatigue test data for precrack $9.5 \mathrm{~mm}$

There are certain limitations in the current study that should be noted. In the current study, the stiffness method for bonded joints has been investigated only for Mode I loading. The work can be further extended to investigate for Mode II and Mode III loading. The FE models for the bonded joints have been developed using elastic constitutive models but adhesives are highly nonlinear, viscoelastic and strain rate dependent materials. The crack propagation in adhesives is modelled using element deletion approach, which consists of deleting elements when stress/strain reaches a defined value, is frequently employed in current FE software. However, this approach has got certain limitations. Once an element is deleted, a local stress concentration is generated that results in fast propagation of failure through all surrounding elements. Using new approaches such as the extended finite element method [45-46], virtual crack closure technique (VCCT) and cohesive zone modelling [47-48]. It may be possible to model to perform crack propagation in adhesives more accurately.

\section{CONCLUSION}

A fracture mechanics-based method for estimating fatigue crack propagation rates and obtain the crack growth rate curves of adhesively bonded joints has been developed and validated in this work. The methodology has been validated again experiments conducted on T-Peel and single lap shear bonded joints with an epoxy-based structural adhesive. It is evident from the plots obtained from ANFIS that with an increase in the precrack length the system becomes more unpredictable.

\section{REFERENCES}

[1] H. Kang, Z. Li, A. K. Khosrovaneh, B. Kang, Z. Li, Fatigue Life Predictions of Adhesive Joint of Sheet Steels. Procedia Eng., 133, 2015: 518-527. https://doi.org/10.1016/i.proeng.2015.12.623

[2] R. D. Adams, J. Comyn, W. C. Wake, Structural 
adhesive joints in engineering. Chapman \& Hall, 1997.

[3] J. A. Bishopp, E. K. Sim, G. E. Thompson, G. C. Wood, The Adhesively Bonded Aluminium Joint: The Effect of Pretreatment on Durability. J. Adhes., 26 (2-3), 1988: 237-263.

https://doi.org/10.1080/00218468808071288

[4] D. A. Dillard, A. V. Pocius, Adhesion Science and Engineering. Adhes. Sci. Eng., Vol.1, Elsevier Science B.V. pp.56-86, 2002.

[5] F. J. Palhares Chaves, Fracture Mechanics Applied to the Design of Adhesively Bonded Joints, by Filipe José Palhares Chaves Supervisor, Thesis for the Degree of Doctor of Philosophy, Faculdade de Engenharia da Universidade do Porto, Portugal, 2013.

[6] M. M. Abdel Wahab, Fatigue in Adhesively Bonded Joints: A Review. ISRN Mater. Sci., 2012: (c), 2012: 1-25.

http://dx.doi.org/10.5402/2012/746308

[7] A. A. M. A. Campos, A. M. P. De Jesus, J. A. F. O. Correia, J. J. L. Morais, Fatigue Crack Growth Behavior of Bonded Aluminum Joints. Procedia Engineering, 160, no. Icmfm Xviii. 2016. https://doi.org/10.1016/j.proeng.2016.08.890

[8] K. Ishii, M. Imanaka, H. Nakayama, Fatigue Crack Propagation Behavior of Adhesively Bonded CFRP / CFRP and CFRP / Aluminum Joints. Journal of Adhesion Science and Technology, 21 (2): 2017: 153-167. https://doi.org/10.1163/156856107780437499

[9] P. A. Carraro, G. Meneghetti, M. Quaresimin, M. Ricotta, Crack propagation analysis in composite bonded joints under mixed-mode $(I+I I)$ static and fatigue loading: a damage-based model. J. Adhes. Sci. Technol., 27 (13), 2013: 1393-1406. https://doi.org/10.1080/01694243.2012.735902

[10] P. K. Sahoo, B. Dattaguru, C. M. Manjunatha, C. R. L. Murthy, Fatigue de-bond growth in adhesively bonded single lap joints. Sādhanā, 37 (1), 2012: 7988.

[11] G. Fernlund, M. Papini, D. McCammond, J. K. Spelt, Fracture load predictions for adhesive joints. Compos. Sci. Technol., 51 (4), 1994: 587-600. https://doi.org/10.1016/0266-3538(94)90091-4

[12] J. Newman Jr U. Zerbst, Engineering Fracture Mechanics. Eng. Fract. Mech., 70 (3-4), 2003: 367369.

https://doi.org/10.1016/S0013-7944(02)00124-8

[13] C. Lin K. M. Liechti, Similarity Concepts in the Fatigue Fracture of Adhesively Bonded Joints. J. Adhes., 21 (1), 1987: 1-24. https://doi.org/10.1080/00218468708074956

[14] A. D. Crocombe, C. Y. Ong, C. M. Chan, M. M. A. Wahab, I. A. Ashcroft, Investigating Fatigue Damage Evolution In Adhesively Bonded Structures Using Backface Strain Measurement. J. Adhes., 78, (9), 2002: 745-776.

https://doi.org/10.1080/00218460213835
[15] V. Shenoy, I. A. Ashcroft, G. W. Critchlow, A. D. Crocombe, M. M. Abdel Wahab, An investigation into the crack initiation and propagation behaviour of bonded single-lap joints using backface strain. Int. J. Adhes. Adhes., 29 (4), 2009: 361-371. https://doi.org/10.1016/j.ijadhadh.2008.07.008

[16] S. Azari, M. Papini, J. A. Schroeder, J. K. Spelt, The effect of mode ratio and bond interface on the fatigue behavior of a highly-toughened epoxy. Eng. Fract. Mech., 77 (3), 2010: 395-414. https://doi.org/10.1016/j.engfracmech.2009.09.01 $\underline{1}$

[17] M. F. S. F. de Moura J. P. M. Gonçalves, Development of a cohesive zone model for fatigue/fracture characterization of composite bonded joints under mode II loading. Int. J. Adhes. Adhes., 54, 2014: 224-230. https://doi.org/10.1016/i.ijadhadh.2014.07.002

[18] Y. Du L. Shi, Effect of vibration fatigue on modal properties of single lap adhesive joints. Int. J. Adhes. Adhes., 53, 2014: 72-79. https://doi.org/10.1016/i.ijadhadh.2014.01.007

[19] F. Moroni A. Pirondi, A procedure for the simulation of fatigue crack growth in adhesively bonded joints based on the cohesive zone model and different mixed-mode propagation criteria. Eng. Fract. Mech., 78 (8), 2011: 1808-1816. https://doi.org/10.1016/j.engfracmech.2011.02.00 $\underline{4}$

[20] X. X. Xu, A. D. Crocrombe, P. A. Smith, Fatigue behaviour of joints bonded with either filled, or filled and toughened, adhesive. Int. J. Fatigue, 16, (7), 1994: 469-477. https://doi.org/10.1016/0142-1123(94)90197-X

[21] T. R. Brussat, S. T. Chiu, S. Mostovoy, Fracture Mechanics for Structural Adhesive Bonds - Final Report, AFML-TR-77-163, Air Force Materials Laboratory, Wright-Patterson AFB, Ohio, 1977.

[22] B. Dattaguru, R. A. Everett, J. D. Whitcomb, W. S. Johnson, Geometrically Nonlinear Analysis of Adhesively Bonded Joints. J. Eng. Mater. Technol., 106 (1), 1984: 59-65. https://doi.org/10.1115/1.3225677

[23] A. J. Kinloch S. O. Osiyemi, Predicting the Fatigue Life of Adhesively-Bonded Joints. J. Adhes., 43 (12), 1993: 79-90. https://doi.org/10.1080/00218469308026589

[24] A. Banerjee, G. Pohit, B. Panigrahi, Vibration Analysis and Prediction Natural Frequencies of Cracked Timoshenko Beam by Two Optimization Techniques - Cascade ANN and ANFIS. MaterialsToday: Proceedings, 4 (9), 2017: 99099913.

https://doi.org/10.1016/i.matpr.2017.06.292

[25] S. Nasiri, M. R. Khosravani, K. Weinberg, Fracture mechanics and mechanical fault detection by artificial intelligence methods: A review. Eng. Fail. Anal., 81, 2017: 270-293. https://doi.org/10.1016/i.engfailanal.2017.07.011 
[26] K. B. Davies C. E. Feddersen, Evaluation of fatiguecrack growth rates by polynomial curve fitting. [ $\mathrm{Ti}$ alloy plate]. International Journal of Fracture, 9, 1973: 116-118.

[27] W. Clark and S. Hudak, Variability in Fatigue Crack Growth Rate Testing. J. Test. Eval., 3 (6), 1975: 454-476. https://doi.org/10.1520/JTE11702J

[28] J. R. Mohanty, B. B. Verma, P. K. Ray, Determination of fatigue crack growth rate from experimental data: a new approach. Int. J. Microstruct. Mater. Prop., 5 (1), 2010: 79-87. https://doi.org/10.1504/IJMMP.2010.032503

[29] B. Mukherjee, A note on the analysis of fatigue crack growth data. Int. J. Fract. Mech. 8 (4), 1972: 449-452. https://doi.org/10.1007/BF00191107

[30] H. G. Munro, The determination of fatigue crack growth rates by a data smoothing technique. Int. J. Fract., 9 (3), 1973: 366-368.

[31] S. M. Beden, S. Abdullah, A. K. A Mohd Ihsan, , Review of Fatigue Crack Propagation Models for Metallic Components Review of Fatigue Crack Propagation Models for Metallic Components, European Journal of Scientific Research, 28 (3), 2009: 364-397.

[32] D. A. Virkler, B. Hillberry, P. K. Goel, The statistical nature of fatigue crack propagation. J. Eng. Mater. Technol., 101 (2), 1979: 148-153. https://doi.org/10.1115/1.3443666

[33] W. F. Wu C. C. Ni, A study of stochastic fatigue crack growth modeling through experimental data. Probabilistic Eng. Mech., 18 (2), 2003: 107-118. https://doi.org/10.1016/S0266-8920(02)00053-X

[34] R. Jones, W. Hu, A. J. Kinloch, A convenient way to represent fatigue crack growth in structural adhesives. Fatigue Fract. Eng. Mater. Struct., 38 (4), 2015: 379-391. https://doi.org/10.1111/ffe.12241

[35] P. Gaur, Investigation of Fatigue Crack Propagation in Adhesively Bonded Joints used in Aluminium Vehicle Structures, M. Res Thesis, Coventry University, 2012.

[36] S. T. Abrahami, T. Hauffman, J. M. M. de Kok, J. M. C. Mol, H. Terryn, Effect of Anodic Aluminum Oxide Chemistry on Adhesive Bonding of Epoxy. J. Phys. Chem. C, 120 (35), 2016: 19670-19677. https://doi.org/10.1021/acs.jpcc.6b04957

[37] G. W. Critchlow, D. M. Brewis, Review of surface pretreatments for aluminium alloys. Int. J. Adhes. Adhes., 16 (4), 1996: 255-275. https://doi.org/10.1016/S0143-7496(96)00014-0
[38] L. F. M. da Silva, P. J. C. das Neves, R. D. Adams, J. K. Spelt, Analytical models of adhesively bonded joints-Part I: Literature survey. Int. J. Adhes. Adhes., 29 (3), 2009: 319-330. https://doi.org/10.1016/i.ijadhadh.2008.06.005

[39] S. J. Spadafora,F. R. Pepe, Comparison of Sulfuric Acid/Boric Acid Anodize and Chromic Acid Anodize Processes. Health \& Environmental Research Online (HERO), GRA and I (4), 1993.

[40] A. E. Bogdanovich, I. Kizhakkethara, Threedimensional finite element analysis of double-lap composite adhesive bonded joint using submodeling approach, Compos. Part B Eng., 30 (6), 1999: 537-551. https://doi.org/10.1016/S1359-8368(99)00026-8

[41] G. Wu, A. D. Crocombe, Simplified finite element modelling of structural adhesive joints, Comput. Struct., 61 (2), 1996: 385-391. https://doi.org/10.1016/0045-7949(96)00101-0

[42] R. A. Smith, The Determination of Fatigue Crack Growth Rates from Experimental Data. International Journal of Fracture, 9 (3), 1973: 352355. https://doi.org/10.1007/BF00049221

[43] M. F. Azeem, M. Hanmandlu, N. Ahmad, Generalization of adaptive neuro-fuzzy inference systems, IEEE Trans. Neural Networks, 11 (6), 2000: 133-1346. https://doi.org/10.1109/72.883438

[44] D. Karaboga E. Kaya, Adaptive network based fuzzy inference system (ANFIS) training approaches: a comprehensive survey. Artif. Intell. Rev., 2018. https://doi.org/10.1007/s10462-017-9610-2

[45] A. Menk S.P.A. Bordas, Numerically determined enrichment functions for the extended finite element method and applications to bi-material anisotropic fracture and polycrystals. Int. J. Numer. Methods Eng., 83 (7), 2010: 805-828. https://doi.org/10.1002/nme.2858

[46] T. Pannachet, L. J. Sluys, H. Askes, Error estimation and adaptivity for discontinuous failure. Int. J. Numer. Methods Eng., 78 (5), 2009: 528-563. https://doi.org/10.1002/nme.2495

[47] G. Geißler, C. Netzker, M. Kaliske, Discrete crack path prediction by an adaptive cohesive crack model. Eng. Fract. Mech., 77 (18), 2010: 3541-3557. https://doi.org/10.1016/i.engfracmech.2010.04.02 $\underline{9}$

[48] C. Gokgol, C. Basdogan, D. Canadinc, Estimation of fracture toughness of liver tissue: experiments and validation. Med. Eng. Phys., 34 (7), 2012: 882-891. https://doi.org/10.1016/j.medengphy.2011.09.030 